\title{
Abnormal Blood Pressure in Prepubertal Children with Sleep-Disordered Breathing
}

\author{
CHRISTIAN GUILLEMINAULT, ANDREI KHRAMSOV, RICCARDO A. STOOHS, \\ CLETE KUSHIDA, RAFAEL PELAYO, MARTINA L. KREUTZER, AND SUSMITA CHOWDHURI
}

Stanford University Sleep Disorders Center, Stanford, CA 94305, U.S.A.

\begin{abstract}
The purpose of this study was to investigate the association between low blood pressure (BP) with mild symptoms of orthostatism, sleep-disordered breathing (SDB) and tilt test results in 7- to 12-y-old children. A retrospective chart review of 301 children, ages 7 to $12 \mathrm{y}$, was initially performed to evaluate the frequency of abnormal BP measurements. Then a prospective study was performed on 7- to 12-y-old prepubertal children with SDB, looking for both abnormal BP and mild orthostatism. All children had polysomnography. Those identified with abnormal (high or low) BP measurements (called "BP outliers") were studied with a new polysomnogram followed by a head-up tilt test as an indicator of autonomic activity. Four of the children with low BP were treated with nasal continuous positive airway pressure and received a second head-up tilt test 3.5 to 7 mo after starting treatment. The prospective study included 78 children, eight of whom were BP outliers. Seven of these outliers had low BP. Compared with all of the SDB subjects, SDB subjects with low BP and indicators of mild orthostatic hypotension had a significantly higher incidence of craniofacial dysmorphism, symptoms of SDB early in life, chronically cold extremities, and dizziness on standing up $\left(\chi^{2}, p=0.01\right.$ to 0.0001$)$. They had a significantly greater drop in BP without evidence of autonomic neuropathy than all other children on head-up tilt testing (Kruskal-Wallis ANOVA with Bonferroni adjustment, $p=0.001$ to 0.0001 ). However, the normotensive SDB controls also had significantly different BP drops than the normal controls ( $p=$ 0.0001 ). The four children placed on nasal continuous positive
\end{abstract}

\section{ABSTRACT}

airway pressure had a nonsignificant trend toward normalization of tilt test response. SDB in prepubertal children can lead to different abnormal stimulation of the autonomic nervous system, with different impacts on BP. The severity and frequency of oxygen saturation drops during sleep, nonhypoxic increases in respiratory effort, and the duration of abnormal breathing are suspected of playing a role in the difference in autonomic nervous system stimulation. (Pediatr Res 55: 76-84, 2004)
Abbreviations
OSAS, obstructive sleep apnea syndrome
SDB, sleep disordered breathing
BP, blood pressure
Pes, esophageal pressure
LBP, low blood pressure
SDBC, sleep disordered breathing control
CPAP, continuous positive airway pressure
AHI, apnea-hypopnea index
RDI, respiratory disturbance index
IRB, internal review board
REM, rapid eye movement
NREM, non-REM
HR, heart rate
BMI, body mass index
EMG, electromyogram
$\mathrm{SaO}_{2}$, arterial oxygen saturation
MSNA, muscle sympathetic nerve activity

In the early 1990s, clinical evaluations of adults with suspected SDB revealed LBP and signs of orthostatic intolerance. A large-scale study was performed thereafter (1). We concurrently investigated whether a similar association could be found in prepubertal children through a retrospective study, briefly summarized later.

Received February 15, 2002; accepted June 19, 2003.

Correspondence: Christian Guilleminault, M.D., Sleep Disorders Clinic, 401 Quarry Road, Suite 3301, Stanford, CA 94305, U.S.A.; e-mail: cguil@stanford.edu

Christian Guilleminault, M.D., Biol.D., was supported by an Academic Award from the Sleep Research Center from NHLBI from the National Institutes of Health. Martina L. Kreutzer was supported by an educational grant from Respironics Inc.

DOI: 10.1203/01.PDR.0000099791.39621.62
Because of the limitations of a retrospective study, a prospective study was planned on newly recruited children, taking into account the retrospective results. The prospective study was aimed at a further investigation of possible abnormal autonomic control in children with hypertension and with LBP and mild symptoms of orthostatic intolerance. A head-up tilt test was planned for 1) hypertensive and LBP Tanner stage 1 (2) children, $7 \mathrm{y}$ and older, with symptoms of orthostatic intolerance and SDB; 2) age, ethnicity, sex, and SDB-matched children with normal systolic and diastolic BP and no clinical symptoms suggestive of mild orthostatic intolerance; and 3) normal control children in a similar age range, recruited as a second comparative group. We based our subject selection on 
our retrospective study findings but also compared the BPs with the criteria outlined in the 1996 Task Force Report on Hypertension (3) and the BP nomograms for children (1993) (4)

This report will present briefly the methods and results of the retrospective study that serves as a base to the prospective study presented thereafter.

\section{METHODS}

\section{Retrospective Study}

Subjects. On the basis of systematic Tanner staging (2), most of the children seen between 1992 and 1996 in the Sleep Disorders Clinic were prepubertal. The children between ages 7 and 11 y had the most complete charts. They had been seen by one of two physicians. Children without sleep-related complaints served as controls and received similar clinical evaluations. Two hundred seventy-one symptomatic and 30 control prepubertal children were studied. None of the children were taking medications. BP measurements were taken after $15 \mathrm{~min}$ of being seated on a bed, at the same circadian time, on the night of the nocturnal polysomnography.

Polysomnography. Polysomnography, using similar recording technology and similar to the one performed in the prospective study (see below), was performed on all 301 children.

\section{Prospective Study}

Subjects. All children with symptoms and polygraphic recording demonstrating SDB and without known genetic craniofacial or endocrine syndromes, seen during the preestablished time period set for the study, were included in the prospective survey. Parents signed an informed consent form approved by the IRB for usage of data collected during clinical investigation for research purposes. Parents signed a separate consent form, approved by the IRB, for all data collection associated with the head-up tilt test.

Five normal control subjects (three girls) were also recruited. They were subjects from the community who were in the overall same age group. Neither they nor their parents had sleep complaints or symptoms of sleep disorders. They had served as control subjects in a previous research protocol, which included a nocturnal sleep recording with esophageal manometry (Pes). They had no evidence of SDB. Parents were recontacted and asked to have their child participate in the tilt test study. They signed informed consent forms approved by the IRB. Children received a new polysomnogram, similar to the ones obtained from the other children, and a head up tilt test the following morning.

\section{Data Collection}

Questionnaire and clinical evaluation. At entry, parents completed a sleep questionnaire with 40 questions on sleeprelated symptoms, family history of sleep-related disorders and otolaryngologic history. All children underwent a general physical evaluation, including BP measurement and sleep disorders evaluation. This systematic evaluation assessed the presence of nasal alar flaring with deep inspiration, enlarged turbinates, craniofacial dysmorphism as in long face syndrome, under-development of the maxilla, high or narrow hard palate, retrognathia, dental crowding, enlarged tonsils and adenoids, and redundant soft palate and elongated uvula. The examiners used a scale from 0 to +3 to indicate the degree of anomaly of the enlarged tonsils, "small chin" and high and narrow hard palate. Adenoids were not scored on a scale; they were visualized by nasal endoscopy and the specialist qualified them as "enlarged" or "normal."

Clinical polysomnography. After their clinical work-up, the children were monitored for at least $8 \mathrm{~h}$ of sleep. The following variables were systematically monitored: EEG (C3/A2, C4/A1, O1/A1, electrooculogram, child and leg EMG), ECG (modified $\mathrm{V}_{2}$ lead), body position (verified with video), and respiration. Extra channels may have been added, depending on the patient's history. Several respiratory channels were used: nasal cannula or pressure transducer system (Protec, Woodinville, WA, U.S.A.), oral thermistor, Pes (Medex Inc., Dublin, OH, U.S.A.), neck microphone, noncalibrated inductive respiratory plethysmography thoracic and abdominal bands, intercostal EMG, and pulse oximetry (Nelcor Inc., Alameda, CA, U.S.A.). When indicated, a transcutaneous $\mathrm{PCO}_{2}$ electrode was added $(5-7)$.

Subjects for tilt test. Index subjects were selected based on low systolic and diastolic BP readings using the criteria obtained from the retrospective study, parental report of chronically cold extremities, or dizziness or lightheadedness on standing abruptly.

Two different control groups were obtained. One group consisted of age $( \pm 8 \mathrm{mo})$, sex, and ethnicity-matched individuals with SDB (SDBC) who did not meet the above criteria for being a test subject. Ethnicity matching was a challenge, particularly in mixed ethnicity children. A total of 10 children with SDB were recruited as control subjects. In addition to the original eight SDBC, two better-matched subjects were found later during the course of the study. Results obtained on the eight children who matched most closely with index subjects are presented.

The other control group consisted of the five normal control children. They received, as mentioned, a new polysomnogram, and a head-up tilt test the following morning.

Head-up tilt test. After having a new polysomnogram, children underwent the tilt test at $0800 \mathrm{~h}$. Subjects, awakened at about $0745 \mathrm{~h}$, were asked to remain supine and were slid from the bed to a gurney to the tilt table. They were loosely strapped to the table with feet left unsupported. The table was brought from a supine to an upright position $\left(90^{\circ}\right)$ within $4 \mathrm{~s}$.

Continuous BP measurements were made during the tilt test with Finapress. The accuracy of Finapress has been evaluated in adults with OSAS, as well as in subjects undergoing tilt testing $(8,9)$. Finapress has also been used on a few sleeping children with high daytime BP. In this study only one child had simultaneous arterial (brachial) and Finapress BP measurement. The readings in systolic BP had discrepancies of up to 4 $\mathrm{mm} \mathrm{Hg}$. However, the differential, defined as the absolute change in BP, was concordant between the two types of measurements. ECG was also continuously monitored using a three-lead ECG montage, which allowed the determination of 
$\mathrm{R}-\mathrm{R}$ interval. The R-R interval and BP were continuously recorded for $60 \mathrm{~s}$ after the table was fully upright.

Follow-up. Four SDB children (two boys, two girls) who underwent head-up tilt testing were placed on nasal CPAP as treatment by clinicians in charge of their care. They were temporarily treated with nasal CPAP because they were underage for orthognathic surgery. Each of the four subjects had a follow-up polysomnogram with nasal CPAP and a morning head-up tilt test at a time convenient for parents between 3.5 and 6 mo after the start of nasal CPAP. The tilt test was performed following a protocol similar to the initial one. CPAP machines were equipped with a memory system downloaded monthly that verified nightly usage of nasal CPAP. Parents and children had clinical interviews and evaluations at the time of their follow-up appointment for head-up tilt testing.

\section{Data Analysis}

SDB polysomnographic definitions. Preestablished definitions were used to score polysomnograms. The apnea and hypopnea events were subdivided into obstructive, mixed, and central. The distinction between apnea and hypopnea was based on the amount of flow limitation at the nose and mouth $(<20 \%$ and $50 \%$, respectively) (10). Events were considered obstructive, central, or mixed based on the presence or absence of chest and abdominal movement and Pes measurement. These events had to last longer than two breaths and end with an arousal or be associated with desaturation of at least $2 \%$.

Abnormal breathing patterns were identified by a fluid-filled sensor the size of an infant feeding tube (1.6 $\mathrm{mm}$ diameter) (11, 12), pediatric nasal cannula/pressure transducer system (Protec) (12), and oral thermistor. These instruments measured Pes, nasal flow limitation, and mouth breathing, respectively (5).

"Abnormal breathing" was also identified by Pes crescendos (13) and sustained abnormal effort (14). A Pes crescendo is a sequence of breaths with an increasingly negative peak endinspiratory pressure with each successive breath (13). A sequence of breaths with a more negative peak end-inspiratory pressure compared with prior baseline without a crescendo pattern is defined as a continuous sustained effort (14). These two abnormal patterns end with either an arousal or a burst of high-amplitude slow waves followed by an abrupt decrease in effort, called a "Pes reversal" $(13,14)$. Another abnormal breathing pattern is an abrupt increase in breath frequency (tachypnea) without an increase in effort $(10,15)$. Tachypnea was defined as an increase in frequency of four or more breaths per minute in young children and three or more breaths in older children for at least $15 \mathrm{~s}$ compared with respiratory rate in the same NREM or REM sleep state. (Normal respiratory rate in NREM sleep is between 16 to 18 breaths/min.)

Polysomnogram analysis. An AHI (number of apneas and hypopneas/h of sleep), an RDI (number of abnormal respiratory events/h of sleep), and an oxygen desaturation index (number of oxygen desaturations $>2 \%$ per hour) were calculated for all subjects. Sleep and wakefulness were scored using international criteria. R-R interval was obtained from continuous ECG recording, and both ECG and data from Finapress were simultaneously collected on a computerized sleep system.
Comparison of the data among hypotensive SDB subjects, normotensive SDB subjects, and normotensive normal subjects was performed with Kruskal-Wallis ANOVA. A Bonferroni adjustment was applied to evaluate significant differences among groups. Comparisons of prenasal CPAP and postnasal CPAP tilt tests were also performed with similar statistical methods. Despite the low number of subjects, a prenasal and postnasal CPAP comparison was also attempted with the Wilcoxon signed-rank test. Comparison of symptoms and signs was analyzed with $\chi^{2}$ statistics.

Analysis of head-up tilt test. The cardiovascular response to head-up tilt testing has been well established. There is an initial decrease in BP and increase in HR, followed by an inverse pattern, and then a stabilization of both measures 45 to $60 \mathrm{~s}$ after the tilt (16-18). The changes are caused by a fall in venous return and a delayed decrease in ventricular stroke volume and reduced carotid sinus, aortic arch, and baroreceptor stimulation. This reduced stimulation triggers a reflex increase in HR and peripheral vasoconstriction.

The short-lived increase in HR peaks between 13 and $16 \mathrm{~s}$ after assuming the upright position, after which the HR rapidly falls. This abrupt HR change is called the "initial HR complex." The switch from one pattern (tachycardia) to another (abrupt bradycardia) occurs between the 17th and 35th heartbeat. A ratio of the R-R interval at heartbeat 30 divided by the R-R interval at heartbeat 15 (called the "HR ratio") is a reliable and validated measure of autonomic nervous system function $(16,18)$. A normal ratio (greater than 1.1) during tilt table testing, and absence of other clinical features of neuropathy, make autonomic neuropathy a very unlikely cause of orthostatic intolerance and LBP (16).

\section{RESULTS \\ Retrospective Study}

The BP measurements were reviewed, and later evaluated based on the "Task force report on high blood pressure in children and adolescents (1996) (3)," after publication of report.

This retrospective BP survey showed that two children (10.8 and $11.2 \mathrm{y}$ ) with BMI between the 82nd and 90th percentile (i.e. overweight) (19) had high BP (141/87 and $138 / 88 \mathrm{~mm} \mathrm{Hg}$, respectively), based on published tables $(3,4)$ Polysomnography demonstrated severe obstructive sleep apnea with repetitive hypoxemic events. The other 299 children were subdivided into subgroups based on age and BMI. The overall mean $\mathrm{BP}$ was $103 \pm 3.1 / / 66 \pm 4 \mathrm{~mm} \mathrm{Hg}$. All BMI percentiles were corrected for age and sex (4); they ranged from the 49th to 78th percentile.

We also identified 21 children with LBP (systolic $<85$ and diastolic $<60 \mathrm{~mm} \mathrm{Hg}$ ) and chronically cold hands and feet and light-headedness or dizziness with sudden rising. None of the hypotensive children had a BMI below the 50th percentile for age and sex, but their BP was significantly lower (more than 2 $\mathrm{SD}$ ) than the mean BP of an age-matched group of children seen in our clinic. All of the 21 LBP children were 9 years old and above. They were all in the SDB group. One also had nocturnal asthma. Sixteen were known regular, loud snorers. 
Four were referred for disrupted nocturnal sleep or daytime fatigue; six, for enlarged tonsils and chronic mouth breathing.

In summary, the retrospective study revealed that high BP was rare in children with SDB, but some prepubertal children with SDB had low systolic and diastolic BP with mild orthostatic intolerance.

\section{Prospective Study}

SDB subjects. Clinical evaluation. Seventy-eight children (28 girls) were analyzed in the prospective study. The mean age was $8.9 \pm 1.1$ y. All were diagnosed with SDB. Signs and symptoms are presented in Table 1. Taking age and sex into consideration, all children had a BMI $\geq 50 \%$ and $\leq 89 \%$ of normative values for age (19) (Table1).

All children per definition were Tanner stage 1 (2). The family (parent and siblings only) histories of SDB children are presented in Table 2. They were based on reported signs or symptoms in at least one of the subjects. Extraction of four wisdom teeth between age 15 and 25 y was considered an indication of micrognathia. Positive history of bruxism was considered as possibly associated with SDB. Family history of hypertension or cardiovascular disease was based on medication intake in one parent or report from the family physician (Table 2).

Polysomnogram. The mean AHI or the number of events lasting $\geq 10 \mathrm{~s}$ terminated by a short arousal or desaturation of at least $2 \%$ per hour of sleep was $9.5 \pm 3.2$. The mean RDI, which included continuous breathing effort and Pes crescendos $(13,14)$ terminating with a short EEG arousal or burst of EMG and return to baseline effort (Pes reversal), was $14.5 \pm 4$ events per hour of sleep. The mean lowest $\mathrm{SaO}_{2}$ was $89 \pm 1.8 \%$. The mean maximal negative Pes was $-22 \pm 6 \mathrm{~cm} \mathrm{H}_{2} \mathrm{O}$. Periodic leg movements (a maximum of 24 in one child) unassociated with arousals were present in four children and were of no clinical consequence.

BP outliers. BP outliers were defined as subjects with systolic and diastolic $\mathrm{BP}<80 / 60 \mathrm{~mm} \mathrm{Hg}$ at bedtime while

Table 1. Signs and symptoms in SDB children

\begin{tabular}{|c|c|c|c|c|c|}
\hline \multirow[t]{2}{*}{ Characteristics } & \multicolumn{3}{|c|}{ Total group BP outliers } & \multicolumn{2}{|l|}{$p\left(\chi^{2}\right)$} \\
\hline & $n$ & $\%$ & $n$ & $\%$ & \\
\hline Regular snoring & 75 & 96 & 8 & 100 & NS \\
\hline $\begin{array}{l}\text { Sleep walking with and without } \\
\text { sleep terror }\end{array}$ & 15 & 19 & 1 & 12.5 & NS \\
\hline Daytime sleepiness & 8 & 10 & 2 & 25 & NS \\
\hline Daytime hyperactivity & 12 & 15 & 1 & 12.5 & NS \\
\hline $\begin{array}{l}\text { Agitated sleep or sweating during } \\
\text { sleep }\end{array}$ & 41 & 52 & 5 & 62.5 & NS \\
\hline Mouth breathing & 78 & 100 & 8 & 100 & NS \\
\hline \multicolumn{6}{|l|}{ ORL examination } \\
\hline+2 and +3 tonsils & 68 & 87 & 3 & 37.5 & 0.0004 \\
\hline Enlarged adenoids & 38 & 49 & 1 & 12.5 & 0.05 \\
\hline Enlarged turbinates & 25 & 32 & 3 & 37.5 & NS \\
\hline \multicolumn{6}{|l|}{ Face } \\
\hline Small/narrow chin & 14 & 18 & 5 & 62.5 & 0.004 \\
\hline $\begin{array}{l}\text { Abnormally high and narrow } \\
\text { hard palate }\end{array}$ & 11 & 14 & 5 & 62.5 & 0.0008 \\
\hline Cold extremities & 5 & 6 & 5 & 62.5 & 0.0001 \\
\hline Dizziness with standing up abruptly & 7 & 7 & 3 & 37.5 & 0.01 \\
\hline
\end{tabular}

Table 2. Family history of SDB children

\begin{tabular}{lccccc}
\hline \multicolumn{1}{c}{ Characteristics } & $\begin{array}{c}\text { Total population } \\
(n=78)\end{array}$ & $\begin{array}{c}\text { BP outliers } \\
(n=8)\end{array}$ & $\chi^{2}$ \\
\hline & $n$ & $\%$ & $n$ & $\%$ & \\
Chronic snoring & 23 & 29.5 & 7 & 87.5 & 0.001 \\
Early wisdom teeth extraction & 14 & 18 & 6 & 75 & 0.0003 \\
History of T and A & 41 & 52.6 & 4 & 50 & $\mathrm{NS}$ \\
Daytime sleepiness/fatigue & 19 & 24 & 3 & 37.5 & $\mathrm{NS}$ \\
Bruxism/mouth guard use & 7 & 9 & 4 & 50 & 0.0009 \\
Hypertensive medication & 5 & 6 & $1 \mathrm{x}$ & 12.5 & $\mathrm{NS}$ \\
$\quad$ intake & $1 *$ & 1.3 & $1 *$ & 12.5 & \\
Cardiac medication intake & $1 *$ & & & & \\
\hline
\end{tabular}

* Father of African American girl.

Abbreviation: $\mathrm{T}$ and $\mathrm{A}$, tonsillectomy and adenoidectomy.

seated and mild signs of autonomic intolerance, or hypertension based on published age-related nomograms (3). Eight outliers were identified in the prospective group. When the total prospective SDB group (including the outliers) was compared with the outliers, they were not significantly different in complaints, except for parental report of chronically cold extremities in $6 \%$ of the total group versus $62.5 \%$ of outliers ( $p$ $=0.0001$; only outliers had such a report). Similarly, report of dizziness or light-headedness with abrupt standing was more prominent in the outliers $(p=0.01)$. A comparison of signs and symptoms and family histories of the outliers to those of the total SDB group is presented in Tables 1 and 2. Craniofacial and oropharyngeal characteristics also had significant differences. Outliers had tonsils at +2 and +3 less frequently ( $p$ $=0.0004)$ but had small and narrow chin $(p=0.0004)$ and abnormally high and narrow hard palate (scale 0 to +3 , with +2 and +3 common in outliers; $p=0.0008$ ) much more frequently. The outliers also had a more frequent parental history of wisdom teeth extraction at a young age $(p=0.0003)$, bruxism or mouth guard usage $(p=0.0009)$, and chronic snoring $(p=0.001)$ than the total SDB group.

One subject with high BP. One outlier had high BP. She was an 11.1-y-old Tanner stage 1 African American girl. She was overweight with a BMI of $22.4 \mathrm{~kg} / \mathrm{m}^{2}$ and a height of $146.5 \mathrm{~cm}$ (BMI about 90th percentile (19)). She had an elevated BP at $138-142 / 97-102 \mathrm{~mm} \mathrm{Hg}$. She had a very large soft palate with markedly enlarged tonsils and adenoids and a narrow oropharynx. A known heavy snorer from early childhood, she had intermittent apnea during her sleep for at least $7 \mathrm{y}$ as noted by her family members. Her AHI was 31 events/h, her RDI was 59 events/h, and her oxygen desaturation index was also $31 / \mathrm{h}$. Her lowest $\mathrm{SaO}_{2}$ was $87 \%$ during NREM sleep and $80 \%$ during REM sleep. BP was abnormally elevated compared with our overall data and published means for age, sex, and height (3, 4).

Seven LBP subjects. The remaining seven outliers (four girls and three boys) had LBP and an increased frequency of mild signs of orthostatic intolerance (Tables 3 and 4) compared with the rest of our subjects and published data $(3,4)$.

Head-up tilt test. Symptoms, signs, and polysomnograms. A comparison of the signs and symptoms seen in all subjects who underwent the head-up tilt test is presented in Table 3, and their BP, AHI, RDI, height, and BMI are presented in Table 4. 
Table 3. Signs and symptoms of subjects undergoing tilt test

\begin{tabular}{|c|c|c|c|c|c|c|c|c|c|c|c|}
\hline & No. & $\begin{array}{l}\text { Chronic } \\
\text { snoring }\end{array}$ & $\begin{array}{l}\text { Sleepiness/ } \\
\text { fatigue }\end{array}$ & $\begin{array}{c}\text { Sleep- } \\
\text { walking }\end{array}$ & $\begin{array}{c}\text { Agitated } \\
\text { sleep/sweating }\end{array}$ & $\begin{array}{c}\text { Cold } \\
\text { extremities }\end{array}$ & $\begin{array}{c}\text { Small } \\
\text { chin } \\
(+2,+3)\end{array}$ & $\begin{array}{l}\text { High, narrow } \\
\text { soft palate } \\
(+2,+3)\end{array}$ & $\begin{array}{c}\text { Tonsils } \\
(+2,+3)\end{array}$ & $\begin{array}{l}\text { Enlarged } \\
\text { adenoids }\end{array}$ & $\begin{array}{c}\text { Reported SDB } \\
\text { onset age }\end{array}$ \\
\hline \multirow[t]{9}{*}{ Outliers } & 1 & + & + & - & + & - & - & - & + & + & $12 \mathrm{mo}$ \\
\hline & 2 & + & - & - & - & + & + & + & - & - & $18 \mathrm{mo}$ \\
\hline & 3 & + & - & - & + & + & + & + & - & - & $9 \mathrm{mo}$ \\
\hline & 4 & + & - & + & + & - & + & + & - & - & $24 \mathrm{mo}$ \\
\hline & 5 & + & + & - & + & + & + & + & - & - & $24 \mathrm{mo}$ \\
\hline & 6 & + & - & - & - & - & - & - & + & - & $10 / 12 \mathrm{mo}$ \\
\hline & 7 & + & - & - & - & + & - & - & + & - & $12 \mathrm{mo}$ \\
\hline & 8 & + & - & - & + & + & + & + & - & - & $15 / 16 \mathrm{mo}$ \\
\hline & total & 8 & 2 & 1 & 5 & 5 & 5 & 5 & 3 & 1 & ave $=15.6 \mathrm{mo}$ \\
\hline \multirow[t]{9}{*}{ SDB controls } & $1 \mathrm{~A}$ & + & + & - & + & - & - & - & + & + & $3 y$ \\
\hline & $2 \mathrm{~A}$ & + & - & - & + & - & - & - & + & - & $5 y$ \\
\hline & $3 \mathrm{~A}$ & + & - & - & - & - & + & + & - & - & $6 \mathrm{y}$ \\
\hline & $4 \mathrm{~A}$ & + & - & - & - & - & - & - & + & - & $6 / 7 y$ \\
\hline & $5 \mathrm{~A}$ & + & - & - & - & - & - & - & - & - & $7 \mathrm{y}$ \\
\hline & $6 \mathrm{~A}$ & + & - & - & + & - & - & - & + & + & $6 \mathrm{y}$ \\
\hline & $7 \mathrm{~A}$ & + & - & - & + & - & - & - & + & + & $6 / 7 y$ \\
\hline & $8 \mathrm{~A}$ & + & - & + & - & - & - & - & - & - & $7 \mathrm{y}$ \\
\hline & total & 8 & 1 & 1 & 4 & 0 & 1 & 1 & 5 & 3 & $\begin{array}{l}\text { ave }=5.9 y \\
p=0.0001\end{array}$ \\
\hline \multirow[t]{6}{*}{ Normal controls } & 9 & - & - & - & - & - & - & - & - & - & \\
\hline & 10 & - & - & - & - & - & - & - & - & - & \\
\hline & 11 & - & - & - & - & - & - & - & - & - & \\
\hline & 12 & - & - & - & - & - & - & - & - & - & \\
\hline & 13 & - & - & - & - & - & - & - & - & - & \\
\hline & total & 0 & 0 & 0 & 0 & 0 & 0 & 0 & 0 & 0 & \\
\hline
\end{tabular}

Abbreviations: +, present; -, absent; ave, average.

Parents noticed certain symptoms, such as noisy breathing or frank snoring, mouth breathing, short interruption of breathing, and agitated sleep, much earlier in the outlier group than in the matched SDB normotensive subjects $(p=0.0001)$.

LBP-SDB outliers $(n=7)$, matched SDB controls $(n=7)$, and normal controls $(n=5)$ were compared. There was no significant difference in height and age among the three groups. The two SDB groups were not significantly different in AHI and RDI.

There were significant differences in systolic and diastolic $\mathrm{BP}$ readings among the three groups as seen in Table 4 . The LBP outliers had significantly lower BP than the SDB controls and normal controls as expected, but the SDB controls, despite having a BP in the normal range, had a significantly higher systolic and diastolic BP than normal subjects $(p=0.0001$ systolic; $p=0.0001$ diastolic).

Head-up tilt test results. Results are presented in Table 5. Raw data and percentages of BP drops and HR changes are given. Percentages are presented to allow better comparison among subjects. There were significant differences among the LBP SDB, normotensive SDB, and control groups. Both SDB groups differed from normal controls. The LBP individuals presented a much more significant drop in BP than the controls ( $p=0.0001$, after Bonferroni correction). This drop occurred despite an increase in $\mathrm{HR}$ at the end of the tilt test and presence of a tachycardic-bradycardic reflex. The LBP subjects also experienced a much larger percentage HR change during the tilt test than in normal controls. This change in percentage [calculated as (maximum HR - minimum HR)/baseline HR] was greatest in the LBP children and intermediate for the normotensive SDB children. This difference in percentage change is related in part to the limited tachycardia seen in SDB children during the first part of the cardiac reflex induced by the tilt test, despite the presence of a 30/15 heart beat ratio above 1.1 .

Follow-up testing on LBP children. Four LBP children were treated with nasal CPAP. These four children had a new polysomnogram performed between 3.5 and 6.4 mo after starting nasal CPAP. In the morning, subjects were given a new head-up tilt test under the same conditions and at the same time as the initial one.

On clinical evaluation, subjects 2 and 4 were scored as Tanner stage 2, but subjects 5 and 7 were still in Tanner stage 1. Subjects 2, 4, and 5 had used nasal CPAP for 5.5 to $6.5 \mathrm{mo}$. Subject 7 had used it for only 3.5 mo. CPAP machine recorders indicated regular use of nasal CPAP for $>7.5 \mathrm{~h}$ per night. Parents reported resolution of snoring, agitated sleep, sweating during sleep, daytime sleepiness, and sleep walking with regular nasal CPAP use. There was no change in incidence of cold extremities.

The results of the repeat tilt test are presented in Table 6. As can be seen, there was a clear difference compared with baseline. Despite the fact that the results were not significant because of the small number of subjects, the percentage of systolic drop at end of tilt testing was much lower $(p=0.07$ Wilcoxon signed-rank test, presence of a trend) with a mean drop of $13 \pm 2.85 \%$ compared with $30.75 \pm 2.34 \%$ before CPAP treatment in these four subjects; the percentage HR change was closely related to the one measured in normal controls. This was associated with a similar tachycardia at beat 15 of the test. 
Table 4. Subjects undergoing tilt test

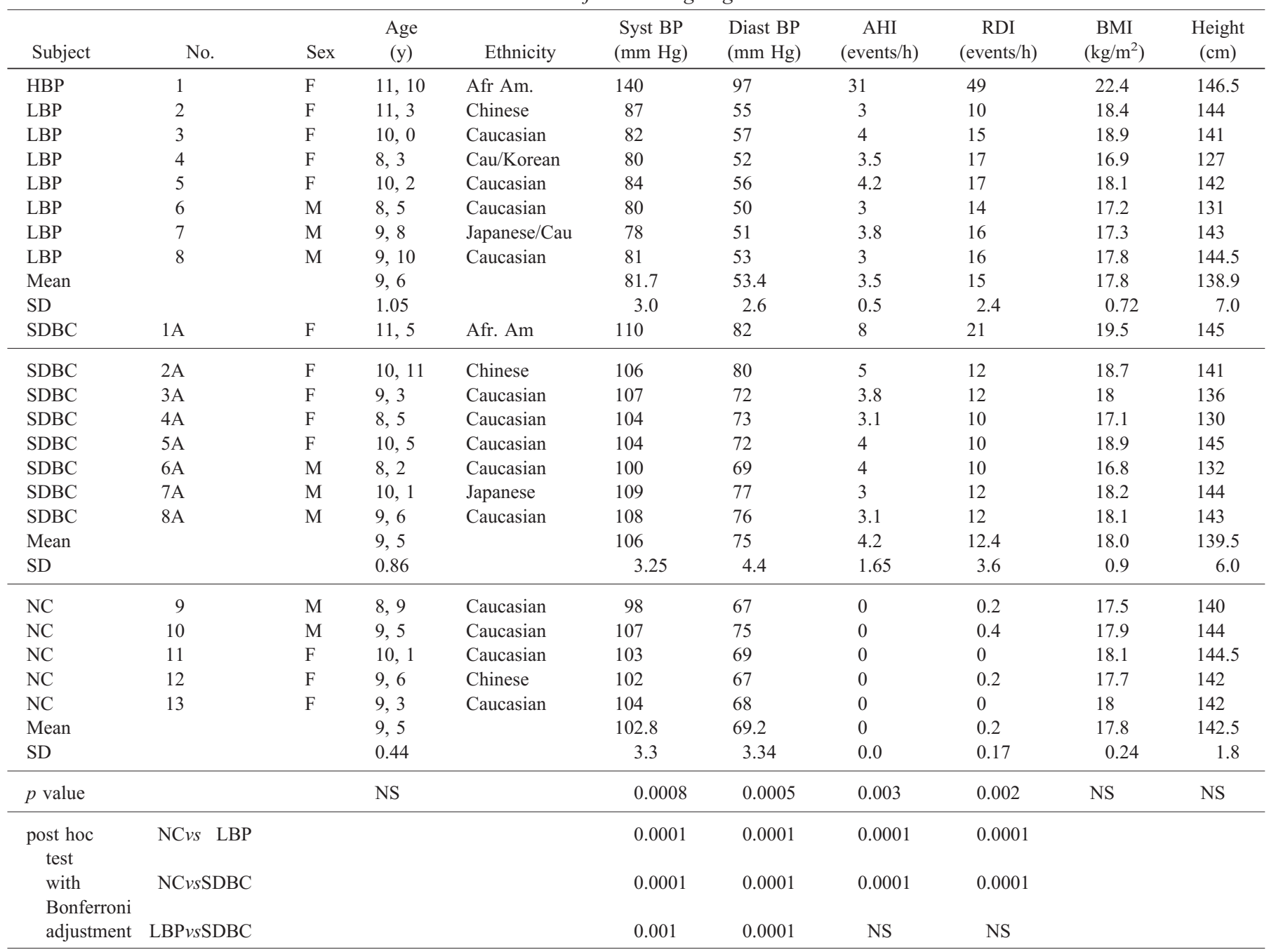

Abbreviations: HBP, high blood pressure; NC, normal control; Cau, Caucasian; Syst, systolic; Diast, diastolic; Afr Am, African American.

$p$ value is from Kruskal-Wallis ANOVA comparing NC, SDBC, and LBP. Post hoc test with Bonferroni adjustment shows that NC were significantly different from SDBC and from LBP SDB for RDI, AHI, and BP results. SDBC were significantly different from LBP for BP results.

\section{DISCUSSION}

BP changes have been reported for many years in association with obstructive sleep apnea. Daytime hypertension was reported as early as 1972 in two nonobese children with OSAS and was corrected with tracheostomy (20).

Investigations have shown that hypertension is a rare finding in OSAS children (21). In our retrospective study mentioned here, only two prepubertal children were found to have hypertension, and in our prospective study, only one child had hypertension. Interestingly, these three hypertensive subjects were all African American. They had severe OSAS, with frequent $\mathrm{SaO}_{2}$ drops and a very elevated AHI for children. In the prospective study, the child with high BP was also the heaviest at $22.4 \mathrm{~kg} / \mathrm{m}^{2}$. The frequent severity of SDB in African Americans compared with whites has already been well documented by Redline et al. (22). Additionally, Marcus et al. (21) have reported that children with OSAS have higher, although nonpathologic, BP readings than matched controls. Our SDB control subjects were similar in this respect to those reported by Marcus et al. (21) (Table 4). In our study, we measured BP at a circadian time that was different from the time used in the large published child population studies $(3,4)$. This is, in part, why we used our own data to define high and low BP. However, our definitions of hypertensive and hypotensive are consistent with those of published tables when height and BMI are taken into consideration (3-4).

The mechanisms by which hypertension can develop in OSAS patients have been well studied. They include 1) recurrent hypoxemia, associated mild hypercapnea, and increased chemoreceptor firing, all of which lead to increased MSNA and increased arterial BP $(23,24), 2)$ arousals during sleep, which directly activate the sympathetic nervous system causing a pressor response $(25,26)$, and 3$)$ recurrent hypoxemia, which triggers endothelial dysfunction leading to impairment of arterial and venous vasodilation (27-31). Nevertheless, not all patients with OSAS are hypertensive, indicating heterogeneity of BP responses to apnea and sleep fragmentation and the possible intervention of other factors.

Hypotension has only recently been emphasized as a change seen with SDB (1). In adults, hypotension and symptoms of 
Table 5. Head-up tilt test baseline results

\begin{tabular}{|c|c|c|c|c|c|c|c|c|c|c|}
\hline Subjects & No. & $\begin{array}{c}\mathrm{R}-\mathrm{R} \\
\text { interval } \\
\text { baseline } \\
(\mathrm{ms})\end{array}$ & Beat 15 (ms) & $\% \mathrm{HR}$ increase & $\begin{array}{cc}\text { Beat 30 } \\
\text { e } \quad(\mathrm{ms})\end{array}$ & $30 / 15$ ratio & $\%$ HR change & $\begin{array}{c}\text { Systolic } \\
\text { BP } \\
\text { baseline } \\
(\mathrm{mm} \mathrm{Hg})\end{array}$ & $\begin{array}{l}\text { BP at end } \\
\text { of tilt } \\
(\mathrm{mm} \mathrm{Hg})\end{array}$ & $\%$ BP drop \\
\hline HBP & 1 & 833 & 618 & 25.8 & 841 & 1.36 & 26.8 & 139 & 110 & 20 \\
\hline \multirow[t]{7}{*}{ LBP SDB } & 2 & 882 & 760 & 15 & 1117 & 1.47 & 40 & 88 & 58 & 33 \\
\hline & 3 & 968 & 821 & 15.2 & 1239 & 1.51 & 43 & 82 & 57 & 30 \\
\hline & 4 & 857 & 745 & 13.1 & 1034 & 1.39 & 34 & 80 & 56 & 30 \\
\hline & 5 & 952 & 820 & 14 & 1204 & 1.47 & 40 & 81 & 61 & 25 \\
\hline & 6 & 952 & 814 & 14.5 & 1190 & 1.46 & 39.5 & 80 & 58 & 27 \\
\hline & 7 & 909 & 790 & 13.1 & 1151 & 1.5 & 40 & 80 & 54 & 33 \\
\hline & 8 & 937 & 809 & 13.7 & 1200 & 1.48 & 42 & 82 & 53 & 34 \\
\hline Mean & & 922 & 794 & 14.1 & 1162 & 1.40 & 39.8 & 81.9 & 56.7 & 30.3 \\
\hline SD & & 41.1 & 30.5 & 0.85 & 69 & 0.03 & 2.85 & 2.850 & 2.7 & 3.35 \\
\hline \multirow[t]{8}{*}{$\mathrm{SDBC}$} & $1 \mathrm{~A}$ & 984 & 855 & 13.1 & 1163 & 1.36 & 31.3 & 100 & 79 & 21 \\
\hline & $2 \mathrm{~A}$ & 1000 & 847 & 15.3 & 1182 & 1.4 & 33.5 & 110 & 88 & 20 \\
\hline & $3 \mathrm{~A}$ & 1034 & 869 & 16.0 & 1321 & 1.52 & 43.7 & 104 & 81 & 22 \\
\hline & $4 \mathrm{~A}$ & 1091 & 917 & 15.9 & 1137 & 1.24 & 20.2 & 104 & 84 & 19 \\
\hline & $5 \mathrm{~A}$ & 1000 & 858 & 14.2 & 1150 & 1.35 & 29.2 & 107 & 84 & 21 \\
\hline & $6 \mathrm{~A}$ & 984 & 838 & 14.8 & 1153 & 1.37 & 32.0 & 109 & 87 & 20 \\
\hline & $7 \mathrm{~A}$ & 952 & 814 & 14.5 & 1122 & 1.38 & 32.3 & 107 & 75.6 & 20 \\
\hline & $8 \mathrm{~A}$ & 968 & 818 & 15.5 & 1132 & 1.38 & 32.4 & 102 & 79 & 22 \\
\hline Mean & & 1004.1 & 851.6 & 14.9 & 1170 & 1.37 & 31.8 & 106.1 & 86.65 & 20.6 \\
\hline $\mathrm{SD}$ & & 46.3 & 35.0 & 1.0 & 68.9 & 0.07 & 6.4 & 2.9 & 4.4 & 1.1 \\
\hline \multirow{5}{*}{$\begin{array}{l}\text { Normal } \\
\text { controls }\end{array}$} & 9 & 845 & 575 & 32.0 & 750 & 1.3 & 21 & 94 & 86 & 8.5 \\
\hline & 10 & 923 & 665 & 28 & 845 & 1.27 & 19.5 & 101 & 92 & 9 \\
\hline & 11 & 984 & 704 & 35.1 & 884 & 1.25 & 18 & 99 & 89 & 10 \\
\hline & 12 & 952 & 702 & 26.6 & 874 & 1.24 & 18 & 98 & 89 & 9 \\
\hline & 13 & 937 & 665 & 34.4 & 846 & 1.27 & 19 & 99 & 90 & 9 \\
\hline Mean & & 928.2 & 662.2 & 31.2 & 840 & 1.27 & 19.1 & 98.2 & 89.2 & 9.1 \\
\hline SD & & 51.7 & 52.3 & 3.8 & 53.04 & 0.02 & 1.2 & 2.59 & 2.2 & 0.55 \\
\hline$p$ value & & 0.008 & 0.0001 & 0.0001 & 0.0001 & 0.0001 & 0.0001 & 0.0001 & & \\
\hline post hoc test & Control vs LBP & NS & 0.0001 & 0.0001 & 0.0005 & 0.0005 & 0.0001 & 0.0001 & 0.0001 & 0.0001 \\
\hline with & Control vs SDBC & 0.03 & 0.0001 & 0.0001 & 0.0001 & 0.0001 & 0.0001 & 0.005 & 0.01 & 0.0001 \\
\hline $\begin{array}{l}\text { Bonferroni } \\
\text { adjustment }\end{array}$ & $\mathrm{LBP} v s \mathrm{SDBC}$ & 0.01 & 0.04 & & 0.02 & & 0.01 & 0.0001 & 0.0001 & 0.0001 \\
\hline
\end{tabular}

Mean and SD values are of LBP SDB, matched SDBC (normotensive), and normal control children. Beat 15, measurement obtained at heartbeat 15 after the tilt test; \% increase, increase in HR compared to baseline; Beat 30, measurement obtained at heartbeat 30 after the tilt test; \% change, change in HR calculated as (maximum HR - minimum HR)/baseline.

$p$ values are from Kruskall-Wallis ANOVA. Post hoc test with Bonferroni adjustment shows that NC were significantly different from SDBC and from LBP SDB; SDBC were significantly different from LBP.

orthostatic intolerance are seen in individuals with increased inspiratory effort during sleep and evidence of mild maxillomandibular dysmorphism involved in the sleep-related upper airway obstruction. The mechanism of LBP and possibly cold extremities and light-headedness on standing are poorly understood. In our subjects there was a much larger percentage HR change during the tilt test than in normal controls. This change in HR percentage was maximal in the LBP children and was intermediate for the normotensive SDB children compared with controls. This difference in percentage is partly related to the limited tachycardia seen in SDB children during the first part of the cardiac reflex induced by the tilt test, despite a 30/15 heart beat ratio above 1.1. A normal ratio eliminates autonomic neuropathy (17) as a mechanism for this weak HR response to a BP drop induced by orthostatism. Other mechanisms must be considered and include the following. Normally, sleep is asso- ciated with predominantly parasympathetic tone, except during phasic REM sleep, when there are abrupt sympathetic bursts. In normal subjects, a Müller maneuver is associated with an acute fall in mean arterial pressure followed by a rise above the mean with cessation of the maneuver (23). The administration of supplemental oxygen attenuates this rebound increase in arterial pressure and simultaneous increase in MSNA (23). All children with SDB and rare $\mathrm{SaO}_{2}$ drops to $95 \%$ will, however, present an increase in respiratory effort and partial or complete repetitive Müller maneuver. The maneuver will only be partial with increased resistance in the upper airway or absence of complete occlusion. The degree of airway collapse will determine the presence of hypopnea versus apnea. Several experiments have also been performed on normal subjects and heartlung transplant patients involving the induction of resistive breathing without hypoxemia and simultaneous recording of 
Table 6. Pre-CPAP and with CPAP tilt test $(n=4)$

\begin{tabular}{|c|c|c|c|c|c|c|c|c|c|}
\hline Baseline SDB children & No. & $\begin{array}{c}\text { R-R } \\
\text { baseline } \\
(\mathrm{ms})\end{array}$ & Beat $15(\mathrm{~ms})$ & Beat $30(\mathrm{~ms})$ & $30 / 15$ ratio & $\begin{array}{c}\% \text { of HR } \\
\text { change }\end{array}$ & $\begin{array}{c}\text { Baseline } \\
\text { systolic } \\
\text { BP } \\
(\mathrm{mm} \mathrm{Hg})\end{array}$ & $\begin{array}{c}\text { End systolic } \\
\text { BP } \\
(\mathrm{mm} \mathrm{Hg})\end{array}$ & $\%$ BP drop \\
\hline \multirow[t]{4}{*}{ Without CPAP } & 2 & 968 & 821 & 1239 & 1.51 & 43 & 88 & 58 & 33 \\
\hline & 4 & 857 & 745 & 1034 & 1.39 & 34 & 82 & 57 & 30 \\
\hline & 5 & 952 & 820 & 1204 & 1.46 & 40 & 80 & 58 & 27 \\
\hline & 7 & 937 & 809 & 1151 & 1.5 & 36.5 & 80 & 54 & 33 \\
\hline Mean & & 928 & 798 & 1157 & 1.46 & 38.4 & 82.5 & 56.75 & 30.75 \\
\hline SD & & 49 & 36 & 89 & 0.05 & 3.9 & 3.8 & 1.9 & 2.85 \\
\hline \multirow[t]{4}{*}{ With CPAP } & 2 & 923 & 643 & 815 & 1.27 & 18.6 & 96 & 85 & 11.5 \\
\hline & 4 & 909 & 659 & 825 & 1.25 & 18.3 & 88 & 75 & 15 \\
\hline & 5 & 984 & 724 & 902 & 1.24 & 18.0 & 86 & 77 & 10.5 \\
\hline & 7 & 968 & 718 & 885 & 1.23 & 17.25 & 87 & 74 & 15 \\
\hline Mean & & 946 & 686 & 856.75 & 1.24 & 18.0 & 89.25 & 77.75 & 13 \\
\hline $\mathrm{SD}$ & & 35.7 & 41.0 & 43.2 & 0.02 & 0.6 & 4.6 & 5.0 & 2.34 \\
\hline \multirow[t]{5}{*}{ Normal controls } & 9 & 845 & 575 & 750 & 1.3 & 21 & 94 & 86 & 8.5 \\
\hline & 10 & 923 & 665 & 845 & 1.27 & 19.5 & 101 & 92 & 9 \\
\hline & 11 & 984 & 704 & 884 & 1.25 & 18 & 99 & 89 & 10 \\
\hline & 12 & 952 & 702 & 874 & 1.24 & 18 & 98 & 89 & 9 \\
\hline & 13 & 937 & 665 & 846 & 1.27 & 19 & 99 & 90 & 9 \\
\hline Mean & & 928.2 & 662 & 840 & 1.27 & 19.1 & 98.2 & 89.2 & 9.1 \\
\hline SD & & 51.7 & 52.3 & 53.04 & 0.02 & 1.2 & 2.59 & 2.2 & 0.55 \\
\hline
\end{tabular}

tidal volume and MSNA (32). Resistive breathing causes a fall in $\mathrm{BP}$, increased respiratory drive during inspiration, and an MSNA decline as lung volume increases $(32,33)$. MSNA is related to the respiratory cycle. It is maximal at end expiration and minimal at end inspiration (32). Finally, if tidal volume is increased, MSNA will be more inhibited during inspiration. Eckberg et al. (34) used baroactive drugs to produce acute changes in arterial pressure that would either stimulate or inhibit arterial baroreflexes. They also observed that MSNA changes were least during inspiration and greater during expiration, and that the relationship of changes in BP to MSNA was affected by the phase of respiration: increases in MSNA activity caused by reduction in BP were significantly less during inspiration than expiration. These changes are concordant with the previously mentioned observations of Seal et al. (32). We have shown that with resistive breathing during sleep (i.e. upper airway resistance syndrome) not associated with hypoxemia, but which may last for repetitive stretches of several minutes $(14,35)$, there is a progressive lengthening of inspiration (inspiration time) with reduction of expiration (expiratory time) (35). Such repetitive stretches, uninterrupted by arousals as shown in adults and children $(12,14,35)$, should lead to progressively less important MSNA stimulation and let the parasympathetic tone be the main modulator of BP with nonhypoxemic resistive breathing, as shown by Seal et al. and St Croix et al. $(32,33)$. One may even hypothesize that if resistive breathing, even to a lower degree than during sleep, is present during the daytime, such prominence of vagal tone will be seen during the 24-h period. One must remember that many SDB children are mouth breathers during the daytime, an indication of some degree of resistive breathing while awake. This would lead arterial BP to be predominantly modulated by parasympathetic tone. Sympathetic activity would be stimulated again by hypoxemic events $(30,31)$. Our control SDB children had a tilt test response that was already different from normal controls even if not as dramatic as the drop seen in the LBP subjects. However, our SDB subjects had mild intermittent hypoxemia, which was neither frequent nor severe enough to induce an increase in sympathetic stimulation, as could be seen in our hypertensive case.

Kahn et al. (36) have also reported that oral belladonna may cause a $50 \%$ decrease in the frequency of OSAS in infants with breath-holding spells. This observation may be another indication of the vagal dominance during nonhypoxemic resistive breathing. Finally, we have also shown in children (37) that resistive breathing during sleep is associated with large swings of the interventricular cardiac septum, resulting in changes in ejection fraction and intermittent echocardiographic ventricular collapse events. These events would lead to intermittent hypovolemia during sleep. These different observations may be taken into consideration when evaluating the mechanisms behind abnormal head-up tilt test on awakening.

Despite experimental data supporting these suggestions, further studies are needed to confirm them, and why a subgroup of SDB subjects had more significant drops in systolic BP at tilt testing is also a matter of speculation. Our subjects appear to have had an earlier development of symptoms. They had a much higher rate of mild craniofacial dysmorphism than the other subjects, and family members had more signs and symptoms of $\operatorname{SDB}(38,39)$. These findings suggest that they had anatomic craniofacial risk factors for a small upper airway at birth or very early in life. This would also suggest a longer period of exposure to resistive breathing than the other SDB group. One point of interest is that when subjected to nasal CPAP for several months, the abnormal response to head-up tilt testing decreased. The changes in head-up tilt testing with nasal CPAP were not significant, and only one subject (no. 5) showed a tilt test response similar to normal controls. Normaliza- 
tion for the other subjects may have occurred after a longer period of time. Clearly a larger number of subjects is also needed here.

\section{CONCLUSIONS}

In summary, our report demonstrates that SDB leads to differential stimulation of the autonomic nervous system; the mechanisms behind these differences must be investigated further.

\section{REFERENCES}

1. Guilleminault C, Faul JL, Stoohs R 2001 Sleep disordered breathing and hypotension. Am J Respir Crit Care Med 164:1242-1247

2. Tanner JM 1962 Growth at Adolescence. Blackwell, Oxford

3. Task Force on High Blood Pressure in Children and Adolescents 1996 Update on the 1987 task force report on high blood pressure in children and adolescents: a working group report from the National High Blood Pressure Education Program Working Group on Hypertension Control in Children and Adolescents. Pediatrics 98:649-658

4. Rosner B, Prineas RJ, Loggie JM, Daniels SR 1993 Blood pressure nomograms fo children and adolescents by height, sex, and age in the United States. J Pediatr 123:871-886

5. Guilleminault C, Pelayo R, Leger D, Clerk A, Bocian RC 1996 Recognition of sleep disordered breathing in children. Pediatrics 98:871-882

6. Marcus CL, Omlin K, Basinki D, Carroll JL 1992 Normal polysomnographic values for children and adolescents. Am J Respir Crit Care Med 146:1235-1239

7. Guilleminault C, Philip P 1992 Polygraphic investigation of respiration during sleep in infants and children. J Clin Neurophysiol 9:48-55

8. Jellema WT, Imholz BPM, Van Goudoever J, Wesseling KH, Van Lieshout JJ 1996 Finger arterial versus intrabrachial pressure and continuous cardiac output during head up tilt testing in healthy subjects. Clin Sci 91:193-200

9. Hirschl MM, Binder M, Herner H, Bur A, Brunner M, Seidler D, Stuhlinger G Laggner N 1996 Accuracy and reliability of non-invasive continuous finger blood pressure measurements in critically ill patients. Crit Care Med 24:1684-1689

10. Guilleminault C, Poyares D 2003 Arousal and upper airway resistance. Sleep Med (in press)

11. Guilleminault C, Stoohs R, Skrobal A, Labanowski M, Simmons J 1993 Upper airway resistance in infants at risk for SIDS. J Pediatr 122:881-886

12. Epstein MD, Chicoine SA, Hanumara RC 2000 Detection of upper airway resistance syndrome using a nasal cannula/pressure transducer. Chest 117:1073-1077

13. Guilleminault C, Kim YD, Stoohs R 1995 Upper airway resistance syndrome. Oral Maxilofac Surg Clin North Am 7:201-214

14. Guilleminault C, Poyares D, Palombini L, Koester U, Pelin Z, Black J 2001 Variability of respiratory effort in relationship with sleep stages in normal controls and upper airway resistance syndrome patients. Sleep Med 2:397-406

15. Guilleminault C, Winkle R, Korobkin R, Simmons FB 1982 Children and nocturnal snoring: evaluation of the effects of sleep related respiratory resistive load and daytime functioning. Eur J Pediatr 139:165-171

16. Ewing DJ, Neilson JM, Shapiro CM, Stewart JA, Reid W 1991 Twenty four hour heart rate variability: effect of posture, sleep and time of day in healthy controls and comparison with bedside tests of autonomic function in diabetes subjects. Br Heart J 65: $239-244$
17. Sprangers RL, Veerman DP, Karemaker JM, Wieling W 1991 Initial circulatory responses to changes in posture: influence of the angle and speed of tilt. Clin Physiol 11:211-220

18. Borst CW, Wieling JF, van Brederode JF, Hond A, de Rijk LG, Dunning AG 1982 Mechanisms of initial heart rate response to postural change. Am J Physiol 243:H676-H681

19. Hammer LD, Kraemer HC, Wilson DM, Ritter PL, Dornbusch SM 1991 Standardized percentile curves of body mass index for children and adolescents. Am J Dis Child 145:259-263

20. Guilleminault C, Eldridge FL, Dement WC 1972 Abnormal breathing during sleep. Sleep Res 1/151(abstr)

21. Marcus CL, Greene MG, Carrol JL 1998 Blood pressure in children with obstructive sleep apnea. Am J Respir Crit Care Med 157:1088-1103

22. Redline S, Tishler PV, Hans MG, Tosteson TD, Strohl KP, Spry K 1997 Racial differences in sleep-disordered breathing in African-American and Caucasians. Am J Respir Crit Care Med 151:682-687

23. Morgan BJ, Denahan T, Ebert TJ 1993 Neurocirculatory consequences of negative intrathoracic pressure vs. asphyxia during voluntary apnea. J Appl Physiol 74:2969-2975

24. Hedner JA, Wilcox I, Laks L, Grunstein RR, Sullivan CE 1992 A specific and potent pressor effect of hypoxia in patients with sleep apnea. Am Rev Respir Dis 146:1240-1245

25. Muenter NK, Watenpaugh DE, Wasmund WL, Wasmund SL, Maxwell SA, Smith ML 2000 Effect of sleep restriction on orthostatic cardiovascular control in humans. J Appl Physiol 88:966-972

26. Somers VK, Dyken ME, Clary MP, Abboud FM 1995 Sympathetic neural mechanisms in obstructive sleep apnea. J Clin Invest 96:1897-1904

27. Carlson JT, Rangemark C, Hedner JA 1996 Attenuated endothelium-dependent vascular relaxation in patients with sleep apnoea. J Hypertens 14:577-584

28. Carlson JT, Hedner JA, Sellgren J, Elam M, Wallim G 1996 Depressed baroreflex sensitivity in patients with obstructive sleep apnea. Am J Respir Crit Care Med 154:1490-1496

29. Duchna HW, Guilleminault C, Stoohs RA, Faul JL, Moreno H, Hoffman BB, Blaschke TF 2000 Vascular reactivity in obstructive sleep apnea syndrome. Am J Respir Crit Care Med 161:187-191

30. Fletcher EC 2000 Cardiovascular consequences of obstructive sleep apnea: experimental hypoxia and sympathetic activity. Sleep 23:127-131

31. Morgan BJ, Crabtree DC, Palta M, Skatrud JB 1995 Combined hypoxia and hypercapnia evokes long-lasting sympathetic activation in humans. J Appl Physiol 79:205-213

32. Seals DR, Suwarno NO, Joyner MJ, Iber C, Copeland JG, Dempsey JA 1993 Respiratory modulation of nerve muscle activity in intact and lung denervated human. Circ Res 72:440-454

33. St Croix CM, Satoh M, Morgan BJ, Skatrud JB, Dempsey JA 1999 Role of respiratory motor output in within-breath modulation of muscle sympathetic nerve activity in humans. Circ Res 85:457-469

34. Eckberg DL, Rea RF, Anderson OK, Hedner T, Pernow J, Lundberg JM Wallin BG 1988 Baro-reflex modulation of sympathetic activity and sympathetic neurotransmitter in humans. Acta Physiol Scand 133:321-333

35. Stoohs R, Guilleminault C 1991 Snoring during NREM sleep: respiratory timing, esophageal pressure and respiratory arousal. Respir Physiol 85:151-167

36. Kahn A, Rebuffat E, Sottiaux M, Muller MF, Bochner A, Grosswasser J 1991 Prevention of airway obstructions during sleep in infants with breath-holding spells by means of oral belladonna: a prospective double-blind crossover evaluation. Sleep $14: 432-438$

37. Shiomi T, Guilleminault C, Stoohs R, Schnittger I 1993 Obstructed breathing during sleep and echocardiography in children. Acta Paediatr 82:863-871

38. Gaultier C, Guilleminault C 2001 Genetics, control of breathing and sleep-disordered breathing: a review. Sleep Med 2:281-295

39. Enlow DH, Poston WR 1990 Facial Growth, 3rd Ed. Saunders, Philadelphia 